\title{
Research on Teaching Method Innovation of Clothing Specialty in Higher Vocational Colleges in Jilin Province Based on Educational Informatization
}

\author{
Yingying $\mathrm{Ge}^{1}$ and Tiantian Yang $^{2}$ \\ ${ }^{1}$ ChangChun University Of Technology,Changchun City, Jilin Province, China, 130012 \\ ${ }^{2}$ ChangChun University Of Technology,Changchun City, Jilin Province, China, 130012
}

Keywords: Education information; Micro-film; Clothing specialty; Vocational students

\begin{abstract}
Based on the problems of the teaching of garments in higher vocational colleges in Jilin Province, this paper introduces the information technology, analyzes the application of micro-class and large data in the education level, and learns the information of "public construction sharing" resource construction mode, probing about the current life of vocational students and their understanding on clothing specialty and studying the feasibility of micro-film as pre-class learning. Considering above, the paper puts forward the teaching method of educational information clothing specialty, designs the overall model, and elaborates the concrete method and implementation details from pre-class, class and after class respectively.
\end{abstract}

\section{Introduction}

The garment industry belongs to the labor-intensive industry, and the main force of the industry is the graduates of vocational students. Students who choose clothing specialty has poor culture quality .they select clothing profession because of the future job and pursuit of fashion. With poor professional knowledge and lack of learning autonomy, professional teaching is greatly affected. Facing vocational students, the traditional teaching methods are difficult to play its role efficiently, which results in a lot of clothing professional teachers begin to research teaching problems.

Information means ${ }^{[1]}$ provide a feasible way of solving these problems. The current people can not be separated from the network. People chat with WeChat, transfer remittances with Alibaba's Alipay and complete a sale without going out of the bank. People will spend more time in watching video, gossip information, playing video games in their leisure time. Unconsciously people prefer the beautiful picture and the context of the video rather than to see the text and the paper media.

Network information as a resource, its best advantage is to share and access easily. It can be applied to teaching of integrating information resources and used in a wider range. Each student can enjoy the best resources. For 40 minutes class, students' generally response is acceptance problem, while some students may be more care about the related professional issues. Teachers can take the "micro class" ${ }^{[2]}$, compress it into small video for a few minute or micro-video collections to explain the important contents of the course. At the same time, you can use about the "big data" [3] to serve the students and grasp the stage of learning and mental state, and make full use of different educational data as a resource, which further help teachers to understand the student situation.

From the point of view of garment specialty, this paper takes the students of garments in higher vocational colleges of Jilin Province as the research object, combining information method with integrating information resources model, micro-class and big data. The paper studies the feasibility of applying micro-film as pre-class learning and puts forward the innovative teaching method of garment specialty. 


\section{Problems in the Teaching of Garment Specialty in Higher Vocational Education}

Basic Quality of Students. Scores of college entrance exam of higher vocational students are generally less about 100 than the bachelor students. Lack of good learning methods and reasonable living habits, they just cope with the final exam in college. Teachers have to select part of professional knowledge to teach for such students, and don't explain in depth so that the professional quality of the students is bound to be limited. Because of their low scores of college entrance examination, they prone prone to produce low self-esteem and negative attitude which leads many vocational students not to love studying, even have psychological inversion for the classroom management. And they are not willing to accept the teacher's criticism. Because higher vocational student' learning ability is insufficient, some students want to learn at the beginning of the new lesson, but they always get a variety of problems that they do not understand. If the textbook cannot explain thoroughly, students will learn less and less and be lack of motivation.

Lack of Sense of Innovation. Clothing profession needs innovative thinking especially the design of clothes. It is said that the dress of the clothes can improve the impression when they meet people. Wearing the suitable clothes, a person can highlight one's beauty and temperament. In the teaching process teachers should cultivate innovative consciousness for students. it is not only the requirements of teaching itself, but also can help students to improve the practical ability of future work. Students incline to study passively. When the teacher teaches the clothing structure drawing on the blackboard and instruct them to draw in hand, students almost do not think about the drawing process. When the teacher teaches fashion painting course, students are required to follow teacher's steps of painting and directly draw according to the template, with the design ability reduced to a simple manual labor.

Single Teaching Form. We have conducted a survey for clothing profession education planning of higher vocational colleges in the part of Jilin Province. A lot of profession education planning is unreasonable. Many students do not understand the professional employment needs and some students even say that their professional learning is useless. Part of colleges set up training courses which is to sew clothes and other mechanical operations. Many students feel that the work on the assembly line is inferior, so they really want to engage in clothing design and clothing promotion courses. However, colleges do not provide such courses and only teach the contents in the textbook. These factors lead to students' confusion on their profession. As for enterprises, the low-level students are not easy to be employed. Most of teachers do not combine the theory in the textbook and the practice in actual work. It is hard to stimulate the enthusiasm of students if teachers just take creativity at their word.

\section{Viable Method of Education Information}

This section mainly describes the teaching methods by information technology from three aspects. From the construction of information resources in colleges and universities, three models: self-built, build jointly and public construction sharing are introduced; From the perspective of micro class, the concept and the development of the status quo are introduced; From the perspective of large data, the characteristics of large data industry in education and the data collection methods are introduced.

Three Modes of Information Resource in the Construction of Colleges and Universities. "Self-built" ${ }^{[4]}$ means to build by themselves. This information construction cannot be separated from the support of net users. The enthusiasm of net users promotes the network information resources to become more and richer. People can view information that they focus on. However, it 
is lack of effective means in resource management information and spam accounted for a high proportion, with many errors in many topics and even with the irrelative information to the topic. Admittedly, everyone can build resources in such a model, but since many people who build these network resources lack the corresponding knowledge, ability and quality, the result is a lot of resources on the network is repeated and lack of originality.

"Build jointly" ${ }^{[5]}$ is to construct resources and share resources in a certain range, referring to an extension of "self-built". The real people who have the ability to build resources will be chosen in this mode, improving the quality of network resources. But because this common way of construction is limited in a certain range, it cannot be shared by the majority of net users. it will not get closer to the information, contrarily it will cause information asymmetry.

"Public construction sharing" ${ }^{[6]}$ stresses that the government and social groups to construct the network information resources. The construction model is more public and could be accessed by the broadest net users. From the perspective of resource development, selecting talents to carry out resource construction and sharing to the majority of users can reduce the different of information on the quality accessed by different regions and industries.

The Concept and Development of Micro-Class. The micro-class is from the 60 -second course offered by Professor LeRoy A.McGrew ${ }^{[7]}$ of the University of Iowa, which is different from the standard 40-minute class. The time of micro-class is very short, but it can describe the problem students are caring about in a very short time and it is easy to accept. On the one hand is the video method; on the other hand is the short-time.

Traditional education methods exist the problems such as poor interaction, heavy information density and low actual utilization etc. There should be some short and practical educational method accepted easily in the teaching level. Schools in Foshan City of Guangzhou use such method at the earliest ${ }^{[8]}$, sorting out a small lesson for the description of a knowledge point, which is easy to be seen. In this process, a micro-course is defined as a carrier which is to carry out the integration of educational resources around a specific knowledge point based on videos. Since 2012, combining a variety of videos into teaching, the micro-class sprung up in recent years. Many colleges and universities also organize the competition of micro-class works. In this process, it is particularly important to think about micro-course application training and application model . The micro-class is not regarded as a small teaching resource, but also an educational activities. Through continuous exploration and practice, micro-class is defined as small online video courses based on the micro-video as core resources.

Education Data Characteristics and Data Collection Methods. Traditional educational data collection is obtained under the consent of students' parents, using statistical analysis in the form of chart. Under the influence of large data, the granularity of data is getting smaller and smaller, and the meaning of data is becoming more and more important. You can use the cloud computing ${ }^{[9]}$, the sensor ${ }^{[10]}$ and related technology to understand the dynamic situations of students and teachers, such as the frequency of questions for each knowledge point, the frequency of teacher's smile, concentration on the course of students by observing the eye gazing of students and so on. At the same time, because of the popularity of the network, education data is no longer stay in paper documents, but more video and pictures.

Different types of educational data correspond to different method of collections. Generally student information, personnel information can be inquired comparably by combining manual collection and relationship database. The data of educational equipment, campus air quality, lighting conditions of classroom and the real-time monitoring of educational progress can be collected by the sensor-sensing way. The electric education resources, such as "micro-class" which 
need to be built specifically, will integrate various network education resources and establish the large public websites. Students attention, action expression, the time of watching micro-class, and the order of browsing them can be converted into electronic log, and then to be analyzed.

\section{Thoughts of Education Methods of Clothing Specialty and Its Innovation}

Considering the status quo of the students of higher vocational colleges in Jilin province, this section tries to analyze their knowledge on clothing, to understand their psychology in this way, and further to elaborate the feasibility of using micro-film as pre-class study.

The Status Quo of Students in Higher Vocational Colleges. Lifestyle can manifest the attitude of a person on his own future and a person's values. Facing the current fierce competition, it is so difficult for undergraduates to find a job that college students couldn't find the right job on the psychological aspect. During college, they may be more thinking about how to enjoy this hard-won college time.

In life, when higher vocational students go shopping, most of them choose affordable clothes that also can highlight their own personality. While students inevitably have to participate in a variety of parties, wearing well or not also shows their life grade in a certain extent, which causes a lot of comparison psychology. In learning, since higher vocational students believe it doesn't matter whether academic study is good or poor, the discipline is very loose. At the same time Teachers are weighed down with teaching in the form and always be late or absent from work and leave early, losing their confidence indirectly.

Understanding on Clothing Profession for Higher Vocational Students. Comparison psychology on wearing of higher vocational students shows they pay attention to personal images and want to dress with their own personalities. It proves the situation that vocational students yearn for life and pursue fashion. Mentioning the clothing, Most of higher vocational students think of models on the $\mathrm{T}$ stage firstly. Part of female students who major in clothing profession dream that one day they could walk on the $\mathrm{T}$ stage or show fashion clothes designed by themselves. Male students want to highlight their youth, wearing beautiful fashion clothes. Some of them wish to win the attention from female students or get a better grade of impression from enterprises on the job market. Some of them choose their own dress based on the stars in the films and plays.

The Analysis on Feasibility of Micro-film as a Pre-Class Learning. The innovation of this paper is to introduce micro-film as a pre-class study. The video can be seen or watched in leisure time or in moving state when the video length is relatively long, about 30 minutes or so. Micro-film [11] can be used for advertising, fashion trends, business publicity and public education and other fields. In essence, it inherits the characteristics of micro-class, short, brief and rich of situations.

The difference of clothing profession from other professions is expression of clothing. The clothing is not a static thing. Firstly, the clothing is used to wear; secondly, the clothing is manifested by the behaviors of life. 

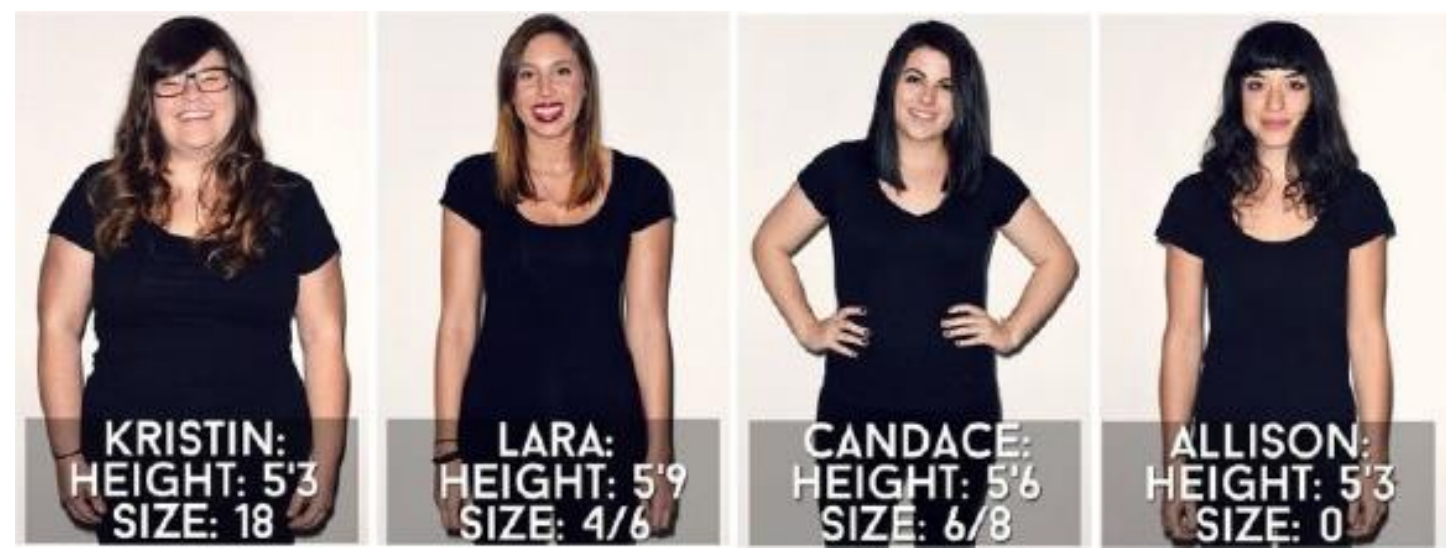

Figure 1. Different people wearing the same clothes

Different people wearing the same piece of clothing feel different, as shown in Fig. 1. The leftmost woman wearing the black t-shirt seems much fatter, while the second left seems more mature, and the rightmost seems good body and white skin comparing to others. Most of the female college students think that the second right woman is similar to their bodies. Basing on the image they consider what it will be like when they wear it so as to choose whether to buy such clothes.
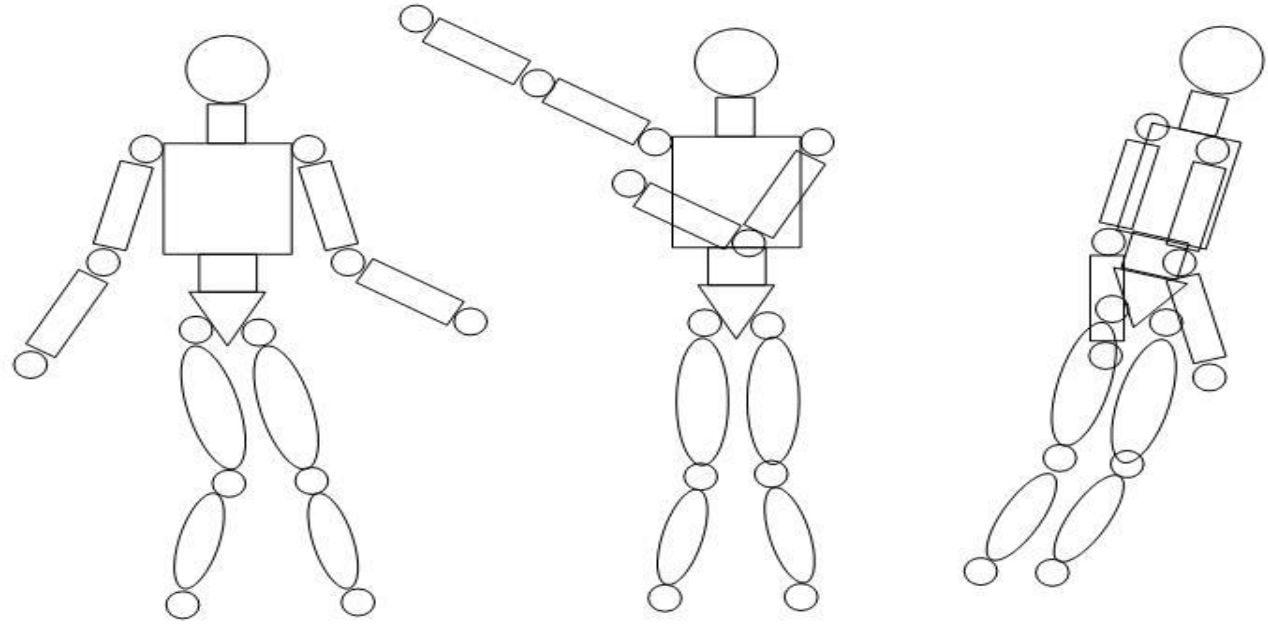

Figure 2. The behavior of people

People will produce a variety of behaviors after wearing clothes. Clothes can highlight the expressional force of behaviors, dressed in different scenes and matching with different clothes. Fig. 2 is the different dances through the human bodies. the left figure shows changes of footsteps with left foot apart, right foot bent, his hands open outward freely; the middle one shows side bending of its feet with right hand toward the chest, left hand stretched out to the sky; the right one shows the body tilting forward widely, the whole body parallel with the body and feet on a line. In real life, there will be a variety of complex behaviors used to express or convey different meanings and the role of clothes is to help people convey them better.

Micro-film is a video media with stories, situations and behavioral arts which clothing design and clothing performances emphasize. It is better to feel the beauty of clothes and life, applying micro-film to clothes performance, combing different scenes with clothes to explain its designation and stress the invisible fashion. 


\section{Teaching Design Based on the Education of Information Technology}

This section synthesizes the above-mentioned methods, including micro-film, education big data, micro-class, sensor and other related technologies to propose the overall design framework. The framework is designed to divide the whole teaching process into three stages, pre-class, class and after school and to describe the practical details of the three stages respectively.

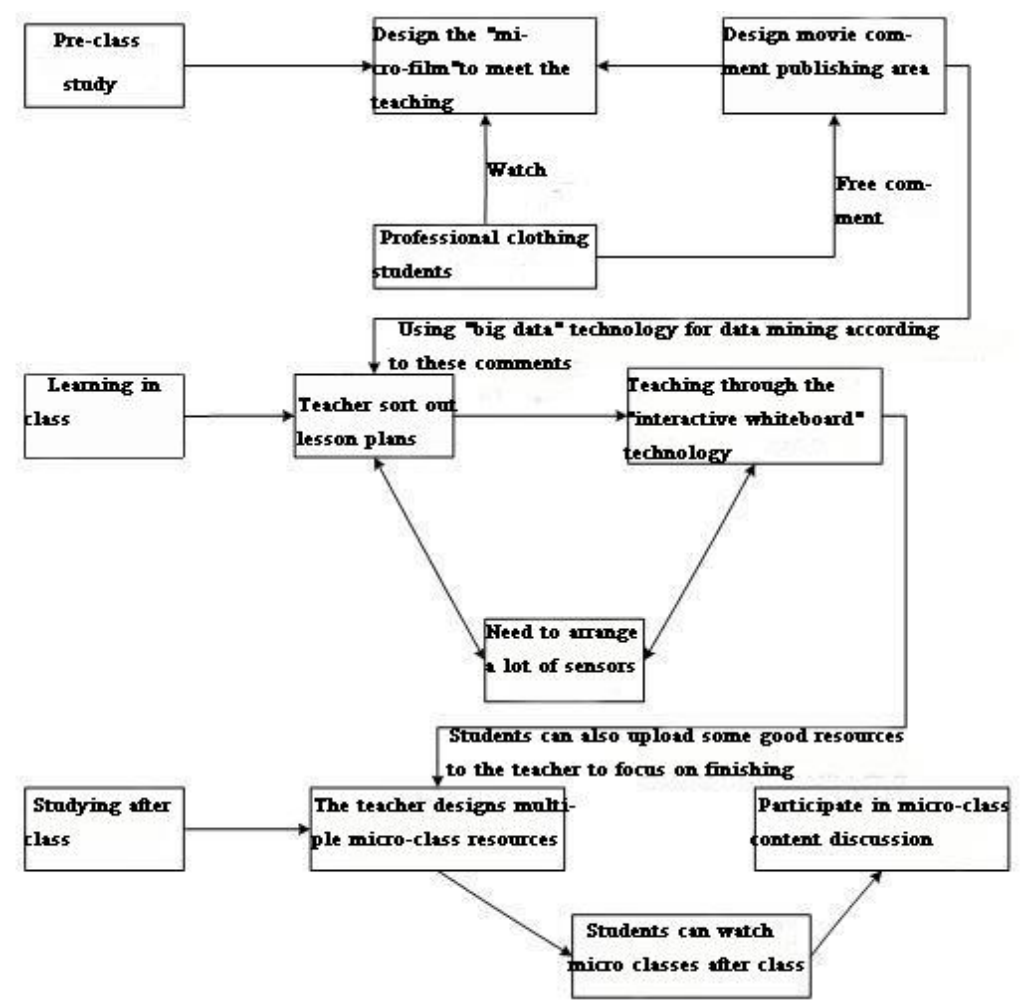

Figure 3. The overall teaching design method of the framework map

As for pre-class stage, vocational students can watch micro-film of courses, publishing some comments. Teachers can conduct correlation analysis on students' comments to know students' interests, confusions, extensive topics, using some technologies of large data. The analysis is useful and helpful for teachers to prepare the lesson plans better. At the time of the lecturing, teachers can communicate with the students better about the content of the course by means of the technology of interactive whiteboard, through the network classroom environment built by the sensor lectures. After class, teachers can organize the topics or the problems which students are interested in into a micro-class. Students can also upload some micro-class resources to teachers and understand the teaching content better through micro-class discussion.

Pre-class Film Review Data Collation. Watching micro-film in pre-class, vocational students can publish some comments on film, a lot of information related to the course can be found from these comments. In the current era of large data, the data are various and chaotic, a lot of hidden information in them. 


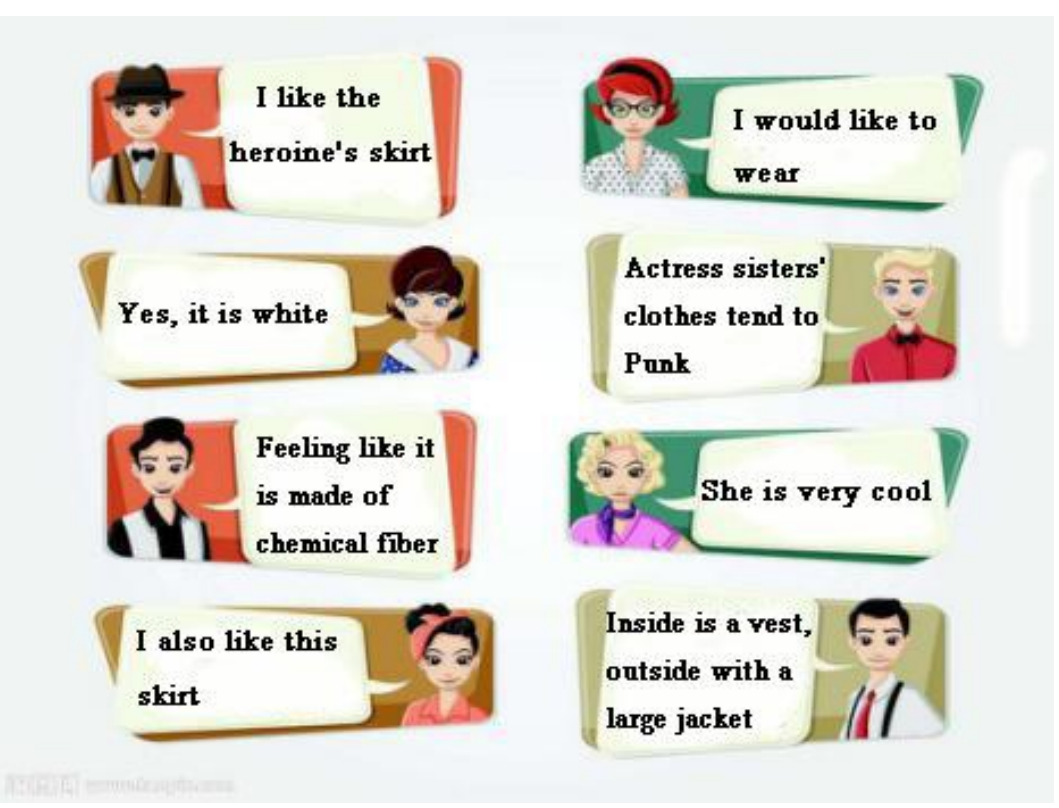

Figure 4. Micro-film commentary

After watching the micro-film, higher vocational students may publish a lot of relevant comments. In Fig. 4, we can see that students are more interested in the actress' and her sister's costumes in the micro movie, referring the color and fabric of her skirt, even its match. In general, these words are relevant to the clothing. Through all kinds of information collection of large data, the data are associated. As for the clothing, a lot of concepts related show costume styling.

A lot of opening source tools can be used for statistical analysis on data collection based on large data level. From the perspective of correlation analysis, Apriori algorithm ${ }^{[12]}$, which is to solve the maximum data item set meeting conditions, can be used and the sub-set meeting the definition of frequent item sets. In a word, there is no subset that does not meet the conditions in maximum data item sets. It is assumed that a garment contains multiple main features, some of which represents a certain teaching point of a clothing course. Sub-feature sets can also constitute the teaching point of a course, a number of sub-features corresponding to each of the main features. Suppose the two main features (A, B) are known, they are unrelated from the main features, but related from the sub-features.

$$
\begin{aligned}
& F_{A}=f_{1}\left(\beta_{1}, \beta_{2}, \beta_{7}, \beta_{9}, \beta_{13}\right) \\
& F_{B}=f_{2}\left(\beta_{2}, \beta_{3}, \beta_{5}, \beta_{9}, \beta_{10}\right) \\
& F_{C}=F_{A} \cap F_{B}=f_{3}\left(\beta_{2}, \beta_{9}\right)
\end{aligned}
$$

Figure 5. Based on the comments appear vocabulary association analysis method

The function represents the related method of correlation analysis. Many vocabularies appearing in the process of conversations seem to be unrelated, but different vocabularies may have multiple features. Extract the features of vocabularies firstly, and then apply intersection set operation to explore the relevance of vocabularies in the comments so as to serve the teaching better.

Application of Interactive Whiteboard and Sensor Technology in Class. Interactive electronic whiteboard ${ }^{[13]}$ is a product for making students and teachers correspond as much as 
possible by improving interactivity basing on the ordinary whiteboard. In some countries, it is very popular. For example, most of primary schools in the United Kingdom had made use of interactive whiteboards ${ }^{[14]}$ in 2007 . As for higher vocational students of clothing profession in Jilin Province, it is a try to apply the whiteboard technology which is not complex, as shown in Fig. 6.

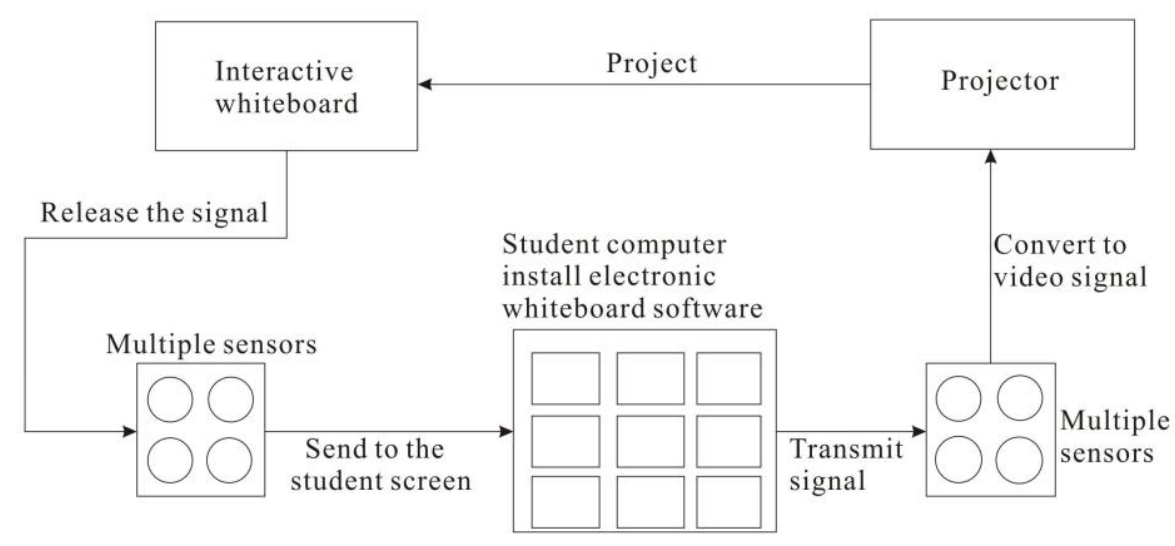

Figure 6. Structure of an interactive whiteboard system

Interactive whiteboard is required to use with the projector, a number of sensor, connecting sensors and electronic whiteboards to the computer by using transmission of computer signals. Under the support of the interactive whiteboard application, the sensor signals are converted to computer-readable images which are presented on the whiteboard by the projector.

The interactive whiteboard system requires the support of sensing signals which determines the success or failure of the overall environment. At present, sensor technologies in favor of interactive electronic whiteboard include: resistive film sensor through the resistance value to achieve sensor positioning; infrared sensor through scanning the objects blocking infrared to achieve positioning; electromagnetic sensor through sending a specific frequency signal to achieve positioning.

Application after Class and Constructive Suggestions. After school, what students should do mostly is consolidate the things learned in the class. The micro-class approach needs to combine application and construction. Many resources of micro-class are not used very well. According to the relevant survey ${ }^{[15]}$, the proportion of demanding on micro-class is $30 \%$ barely, the proportion of downloading the relevant resources just $15 \%$. The value of micro-class can be shown only in the shared application. It is necessary for teachers to focus on quality, especially on training and learning how to design micro-class during preparing their teaching.

We recommend playing micro-class resources intensively, experts making comments on them. Communicating with students on the contents and the designs, the further improvement should carry out according to their reactions. The contents of micro-course must be logical and be arranged systematically on some topics. Teachers can create excellent video resources of micro-class, in the way of teamwork and brainstorm to improve the efficiency. In the process of creating, teachers should discuss frequently with students about contents of micro class and understand their confusions in subject learn.

\section{References}

[1] Liu Changying. Using information technology to improve the effectiveness of educational activities [J]. Early childhood education, 2014 (Z4): 84-84. 
[2] Zhang Xia. On the normalization of the application of micro-class education [J]. China Information Technology Education, 2015 (23): 87-90.

[3] Lu Hongyin, Lian Defu, Nie Min, etc. Large data to lead the future of education: from the results of the forecast [J]. Large data, 2015, 1 (4): 118-121.

[4] Wang Mengying. Digital library information resources quality factors analysis [J]. Journal of Library and Information Sciences in Agriculture, 2015, 27 (3): 43-46.

[5] Chen Lin. Creation of digital learning resources public building to enjoy the model [J]. China Audio-Visual Education, 2012, (1).

[6] Zhao Xiaosheng. Digital education resources allocation model change - from sharing to public construction sharing [J] .Electronic Education Research, 2015 (4): 70-75.

[7] Pang Jia Lu, Rong Xiaofang. On the promotion of micro-class teacher professional development [J]. Hebei Education: Comprehensive Edition, 2015 (9).

[8] Feng Zhihui, Zheng Xiaodan. New definition of micro-class: from technology development to effective design - An interview with Professor Hu Xiaoyong of South China Normal University and teacher Hu Tiesheng of Foshan Education [J] .Development, 2015 (4): 56-60 .

[9] Zhang Ze Ang,Wu Jiawei. Research on Educational Information Platform based on Cloud Computing [J]. China Distance Education: Comprehensive Edition, 2010 (6): 66-69.

[10] Sun Daner, Wei Silin. Foreign science education in sensor technology teaching research and enlightenment [J]. Distance Education Journal, 2012, 30 (05): 50-55.

[11]Zhang Hai, Wang Yining. New media environment microelectronics in the field of education and learning prospects: review and outlook [J]. Modern distance education, 2013 (4): 70-74.

[12] Yang Qiang. Application of improved Apriori algorithm in educational information mining [J]. Journal of Tangshan Teachers College, 2011, 33 (5): 46-48.

[13]Xiong Sufen. Interactive whiteboard in the classroom teaching application [J]. Cultural and educational materials, 2012 (20): 161-162.

[14] Chen Di. Interactive media support under the classroom teaching research [D]. Huazhong Normal University, 2012.

[15] Hu Tiesheng, Huang Mingyan, Li Min. Three stages of the development of micro-class in China and its implications * [J]. Distance Education Journal, 2013 (04): 36-42. 